\title{
A Visual Study of Jiangxi Music Non-legacy Knowledge Based on VR Technology
}

\author{
Chuanli Liu ${ }^{1}$ Chunbao Cai ${ }^{1}$ Lizhi Wei $^{1}$ \\ ${ }^{1}$ Nanchang Vocational University,Nanchang,Jiangxi,330004,China
}

Project No. GJJ206309 of Science and Technology Research Project of Jiangxi Education Department "Visualization of Music Non-legacy Knowledge Based on VR Technology

\begin{abstract}
As the development of society and the innovation of science and technology, VR technology, as a new product of the 21 st century, brings us not only shock, but a fusion of innovation. As a hot spot in this era, VR technology is also called "spiritual technology ". This technology makes a virtual world by computer, makes the diversified information merge into a three-dimensional body information, through the equipment, can make people in a virtual real environment can not extricate themselves. The progress of science and technology has always surprised us ." VR technology "is a comprehensive innovation for all walks of life. How to make Jiangxi music non-legacy knowledge get attention again, VR technology should be a breakthrough.
\end{abstract}

\section{Introduction}

At this age of science and technology, the spread of culture needs to seek opportunities through new ways, VR technology as a hot spot in the 21 st century, it brings a feast of science and technology. VR technology as a new medium of cultural protection, its mission is to make Chinese culture re-line the cultural stage. VR technology and Jiangxi kind of non-legacy knowledge culture fusion is not so much an innovation, but also a reform, it uses its most beautiful side to show in everybody's eyes, lets Jiangxi culture carry forward again.

\section{VR Overview of Virtual Reality Technology}

\subsection{Development of VR technology}

VR technology, commonly known as virtual reality, is a virtual world created by computer system, which is formed by computer graphics system and various realistic control devices. In this three-dimensional world, provide visual, auditory, tactile and a series of sensory simulation, so that you seem to live. VR as a new technology in the 21 st century, the demand for VR technology is increasing in all walks of life. At present, VR technology has been widely used in industry, medical treatment, education and other fields, which has a good effect on people's perceptual experience. Nowadays, virtual reality technology has become more and more mature and developing. According to the project statistics of $805 \mathrm{VR}$ technologies in the world, the results show that the proportion of entertainment, education and art is as high as 21.4 , military aviation 12.7, medical 6.13, robot 6.21 and commerce 4.96. Below is a scale of market demand analysis for VR technologies across industries[1].

Table 1. Proportion of demand VR technology banks

\begin{tabular}{|c|c|}
\hline \multicolumn{2}{|c|}{ Proportion of demand VR technology banks } \\
\hline $\begin{array}{c}\text { Entertainment, Education and } \\
\text { Arts }\end{array}$ & $21.4 \%$ \\
\hline military aviation & $12.4 \%$ \\
\hline medical & $6.13 \%$ \\
\hline robot & $6.21 \%$ \\
\hline commerce & $4.96 \%$ \\
\hline others & $48.9 \%$ \\
\hline
\end{tabular}

\subsection{Basic functions of VR technology}

As a hot spot in this era, VR technology is a multidisciplinary technology, which includes a series of social disciplines, such as multimedia, network, sensor, simulation and three-dimensional display. Nowadays, virtual reality technology is recognized as the most influential technology in the world. Its development affects the progress of various industries. VR technology uses the principle of simulation, through computer information technology, multimedia technology, Internet technology and electronic technology to make devices form a perceptual world, can make people feel the same in this perceptual world. VR technology provides strong support for VR simulation system technology through lifelike and real-time interaction. In the whole virtual

\footnotetext{
*Corresponding author's e-mail:qgjxzbt@163.com
} 
reality system process, the system must satisfy three characteristics, first, the user's immersion in the virtual world, in the virtual process to give the user an ability to distinguish between right and wrong, is the user in the whole body and mind into the virtual world, To watch and feel makes him feel that in this world, everything is true, as in his real life. Second, the controllability of the virtual world refers to the user in the virtual process, through the use of simulators in the virtual world sense things, when there is something in the hands of the feeling is, you can feel in the illusory world weight, Can easily capture the illusory world things, let you have a real feeling. Third, the user's autonomy to the virtual world, through a virtual multidimensional space, the user through their own perception ability, obtain multi-party information so that they have the initiative, seek more opportunities to solve problems[2].

\section{VR technology for Jiangxi music non- legacy knowledge inheritance significance}

\subsection{VR technology will be an opportunity for the development of Jiangxi music non-legacy knowledge}

Jiangxi music non-legacy knowledge is of great significance to the composition of non-legacy protection in our country. It has high value cultural information resources and protects non-legacy culture in the whole historical process. How to re-innovation is the most important part of Jiangxi music culture.

VR technology has played a key role in entertainment and art in recent years, making our lives more exciting. VR technology uses virtual reality to provide advanced protection measures for restoring Jiangxi music nonheritage cultural knowledge[3]. Cultural inheritance can not be separated from the innovation of science and technology. VR technology, as the innovation combination of Jiangxi music non-legacy knowledge, will lead to a new direction for the spread of culture. In the process of national deployment, the use of virtual reality technology to promote Jiangxi music non-legacy knowledge is the turning point of cultural innovation and development. VR technology and Jiangxi music integration, is an innovation, not only to make up for Jiangxi music non-heritage knowledge inheritance and dissemination process deficiencies, but also let people re-understand Jiangxi music non-heritage knowledge culture, This is of great significance to the whole Jiangxi music non-heritage knowledge.

\subsection{VR technology is a valuable embodiment for the inheritance of Jiangxi music non-legacy knowledge}

Value is the embodiment of a culture, Jiangxi music nonlegacy knowledge in the whole history has a very important value. As a tool to break down barriers, VR technology breaks the constraints of time and space. In the illusory three-dimensional space, in the most intuitive way, Jiangxi music non-legacy knowledge can be re-emerged. When all non-legacy knowledge is recorded, the value of inheritance will become larger and find the inheritor for Jiangxi music non-legacy knowledge[4].

\section{The Present Situation of Jiangxi Music Non-legacy Knowledge}

\subsection{The Rise of New Music and the Decline of Traditional Music}

One is the development of the times, accompanied by collision, in this road of development, the two times collision process, one high and low is their sharp contrast. The rise of new music may be inevitable in the development of this world. Human beings always incorporate fresh elements and fresh affairs into music. With the passage of time, the way of music expression changes at any time, and the multi-element music becomes the current trend. And those traditional music is gradually forgotten and ignored, resulting in the inability to get fresh blood to pass on.

\subsection{The lack of cultural interest among the new generation of young people inheritance difficult}

In recent years, with the continuous changes in the economic market, Jiangxi Province, in the whole process, the economic system is constantly changing, class distribution has also changed significantly, people also have their own unique views on culture. There is a higher standard for the pursuit of organizational life. Therefore, Jiangxi non-culture has also suffered the impact of various cultures. As a new generation of young people, their interest in traditional intangible culture has gradually disappeared, especially the intangible cultural heritage of music has even appeared the situation of no one inheriting and losing culture. The attitude of the new generation of young people to ignore the traditional intangible cultural heritage is an important reason for the loss of most musical intangible cultural heritage[5].

\subsection{A fault crisis}

At present, the most severe situation of cultural heritage is that no inheritor, no one wants to learn, which leads to a lot of inheritance is about to appear fault crisis. These inheritance is more harsh for the selection of people, most of them are old inheritance, and aging inheritance is undoubtedly the most difficult in the current inheritance, the speed of inheritance will be fast, once there is no suitable inheritor, There will be a fault crisis in this culture.

\subsection{Culture is spread in a single way}

Jiangxi music non-legacy knowledge in each era has its own development characteristics, in the eyes of Jiangxi people also have a different position. But with the development of the times, Jiangxi music non-legacy 
knowledge culture also encountered unprecedented challenges, cultural knowledge and spirit slowly weakened, people's love for it can not return to the past. The main reasons are as follows: first, the art communication mode of Jiangxi music is relatively single, the lack of innovation to its own music, and the lack of culture that truly combines the regional characteristics of Jiangxi people. Second, blindly follow the trend, want to emulate other music culture but forget their own culture. Third, lack of new ways to open up the market, continue the old way to spread culture. It is these points that Jiangxi music non-legacy knowledge dissemination process has been in a dangerous state, need a new communication interface, break through this obstacle[6].

\subsection{Inadequate local protection policies}

The protection and inheritance of intangible cultural heritage can not be separated from the government's policy, and the process of cultural inheritance is accompanied by forgetting. If there are no good policies and measures, culture will slowly be forgotten and disappear in the vast crowd. Only by investing a lot of human, financial and material resources to protect the government can culture be preserved and continued.

\section{Application of VR Technology to the Non-legacy Knowledge of Jiangxi Music}

\subsection{Into a completely new experience}

For most people, listening to songs is simply listening to words and sounds, but the most valuable content," artistic conception ", is often ignored. Jiangxi music, as a member of non-legacy knowledge, can only experience artistic conception by watching it in person, which is difficult to meet.

\subsection{The transmission of culture will have a new development}

Jiangxi music as a non-heritage knowledge protection object, its survival and development especially emphasizes the inheritance of tradition, Jiangxi music to the emotional description is more direct, can vividly show ups and downs, let the audience feel the same. But in the process of transmission, there is no opportunity to go to the stage of the world. And this opportunity is VR technology, for music performance, virtual reality technology[7], not only bring new ways of music dissemination, but also should be created new space. A multi-dimensional space of performance, VR technology simulation of real-action performance, the diversity of forms, can make art have a stable dissemination space.

\subsection{Let music escape the bondage of time and space}

In this changing world, things are shuffling, as if "change" has become the same theme of the world, including music.
From traditional music to digital music, the form of music has changed a lot, people also have a new understanding of music. Throughout the various times of music it has its own form of expression, Jiangxi music non-legacy knowledge in its history of the river, it uses its unique rhythm and emotion, conquered many people. Now, it is in the sea of smoke can not reproduce the eyeball, there is a barrier, so that it can not cross. What opportunity can break this barrier[8], I think VR technology is its breakthrough, using VR technology to bring people into the scene of that era, relive the feelings of that era, let reality and the past reconnect, Let the new era young people understand Jiangxi local customs, music rhyme. Jiangxi music non-legacy knowledge can reflect its most fundamental value.

\subsection{Review music and improve aesthetics}

Music as a human emotional expression, its rhyme story at any time affect our emotions. A prosperous performance, every time can fluctuate our hearts. When technology becomes a performance, traditional music will be a review. As the medium of Jiangxi non-legacy music, VR virtual technology can make people appreciate the culture of traditional music and feel the cultural atmosphere of that era. As long as you feel the culture of the times, music will lead you to that world and sublimate your heart.

\subsection{Cultural heritage needs to continue}

In the rivers of the years, Jiangxi music has been destroyed many times, some have disappeared in the vast universe, some stick to the traditional heritage, imagine the future, Our descendants will never see the cultural heritage left by their ancestors again. What a sad thing it should be. If the use of VR technology to retain all non-heritage skills, Jiangxi music non-heritage knowledge will be permanently preserved, so that continued[9].

\section{Strategies and Suggestions on the Protection of Jiangxi Cultural Non- legacy Knowledge Based on VR Technology}

\subsection{Based on VR technology to protect Jiangxi culture non-legacy knowledge implementation strategy}

6.1.1 By using VR technology, the original
preservation of all Jiangxi non-legacy knowledge.Jiangxi music non-posthumous knowledge of the greatest value lies in the historical, thousands of years of historical heritage of culture, with its own way of transmission, as long as not arbitrarily changed, this historical value can continue, VR technology as the media of Jiangxi music non-heritage knowledge, Its function lies in keeping this historic culture intact, recording all processes in all aspects, vividly and vividly displaying cultural heritage and breaking regional boundaries. No 
matter how the society develops, its inheritance is still there. As long as you enter the illusory world of preservation, you can understand the oldest memory skills.

\subsubsection{By using VR technology, non-posthumous} culture can be brought back to the stage. The most direct way to protect culture is to make culture go to the stage again, VR technology use scientific and technological performance to make more people attract attention, let more people watch Jiangxi music nonheritage cultural tradition. For example, the Beijing Museum's collections are digitally viewed and the Shaanxi Terracotta Army's Digital Museum, all of which are repackaged by VR technology to absorb sound in new forms. If Jiangxi music non-legacy knowledge seize this opportunity, can let their own culture, re-expression, reattract people's attention, let the cultural road forward, reentering the cultural stage.

\subsubsection{Building an exhibition space of Jiangxi music} non-legacy culture by using VR technology. With the increase of the national policy on the protection of cultural heritage, the design of cultural heritage exhibition hall has become an upsurge. If we use VR technology to create a cultural exhibition belonging to Jiangxi music class, it will be a new form of expression. Jiangxi music non-legacy knowledge itself has historical value and exploration, the integration of all non-legacy culture will become a cultural appreciation, it will have a strong attraction, more people to explore and learn[10].

6.1.4 By using VR technology, Jiangxi music will interact deeply with people.Virtual reality interaction refers to the computer simulation environment in the aspects of vision, hearing, touch, smell and taste, in which users interact to produce a new experience. Jiangxi music non-heritage cultural scene made by VR technology, multi-form performance can drive people's emotional emotion at any time, when the process of interaction with it, people will further understand Jiangxi music nonheritage knowledge. Interaction is a passive acceptance process that allows you to subconsciously accept it.

\subsubsection{Building brand culture by using VR technology} using VR technology. Building a Jiangxi music brand by VR technology is not only of great significance to the inheritance and dissemination of Jiangxi non-heritage knowledge culture, but also a continuation of the cultural spirit of Jiangxi music non-heritage knowledge. Jiangxi music non-legacy knowledge culture records the historical process, its tradition and knowledge, is the entire Jiangxi non-legacy culture has the important historical basis. At present, science and technology are the productive forces of social development, and the integration of VR and Jiangxi music non-legacy knowledge and culture has a new guide to the spread of Jiangxi culture. The brand culture will promote the development of the whole industry. The brand strength of Jiangxi music knowledge culture will give art a new way for all Jiangxi non-legacy culture, so that more people can accept her and understand it[11]. At the same time, it has a leading role in the inheritance of Jiangxi's non-heritage culture, which makes Jiangxi's non-heritage culture have new connotations and tastes, and makes the culture have a new cultural charm, so that Jiangxi's music non-heritage culture can speak and go out of China.

\subsubsection{Dissemination of cultural exhibitions through} $V R$ technology.In the current era of Internet science and technology, whether it is cultural propaganda or transmission of information, most institutions will choose to carry out exhibitions, want to convey the information, so that their own publicity to achieve greater results. VR and Jiangxi music non-legacy knowledge culture fusion can be through the exhibition way to promote, so that more people know Jiangxi music non-legacy knowledge culture. The transmission of culture must open up a new way, the development of the exhibition is a new means for Jiangxi music knowledge culture, using the image of the exhibition to declare themselves, improve their own value has a very important role.

\subsection{Based on VR technology to protect Jiangxi cultural non-legacy knowledge implementation recommendations}

6.2.1 Stick to tradition and develop together.As the frontier of social development, VR technology has changed along this era, and Jiangxi music knowledge is fixed in that era. Although culture should keep pace with the times, the root of essence in the process of seeking development can not be changed. Once changed, tradition will not be that traditional culture. Jiangxi music nonlegacy knowledge can use VR technology to board the ship, but must not rely solely on it ashore. Only to show their own light, is based on the fundamental. Steady progress and coordinated development is the survival of Jiangxi music non-legacy knowledge[12].

\subsubsection{Follow the rules and strive for excellence. The} law is moving and follows the natural development. The development of any thing must follow the thing itself, only conform to the law can be done, reverse law, will only be difficult, to destroy. VR technology should be applied to Jiangxi music knowledge, pay attention to culture itself, strive for excellence, find out their own law before moving forward.

\section{Conclusion}

With the rapid development of science and technology, the development of VR technology will become the most important way to inherit Jiangxi music culture. Based on the characteristics of virtual reality, VR technology has broken many barriers in protecting Jiangxi music nonlegacy knowledge and solved the limitations of traditional culture communication. As the VR technology becomes more and more perfect in the future, virtual reality technology will perfectly fit Jiangxi music non-legacy 
knowledge, show its uniqueness, vitality and inheritance, and carry on the inheritance and dissemination in the multi-dimensional angle of time and space, so that Jiangxi music non-legacy culture can go to the world stage again.

\section{References}

1. Tian,Q.(2010)A Case Study on the Theory and Practice Protection of Music Non-legacy Projects[D].Anhui Literature and Art Publishing House.

2. Liu,J.Huang,J.M.Zhang,H.Y.(2019)The

Development of Rural Folk Music in Shangrao[J].Arts Assessment.

3. Wang,Y.L.(2020)Application and Exploration of 5G Technology in Music Education[J].Media Forum3.

4. Fang,C.H.Yang,J.Ma,K.Zhang,X.Y.(2019)Study on the Communication Mode and Protection of Shifang Non-posthumous Culture in the New Media Context[J].New Media Research.

5. Ning,F.Hou,J.J.(2016)Study on the Communication Strategy of Intangible Cultural Heritage in the All Media Age[J].Journal of Nanchang Normal University.

6. Shi,S.M.(2020)The Innovation and Promotion of Non-posthumous Culture from the Perspective of the Whole Media[J].Chinese character culture.

7. Ji,Y.(2020)Research on the Application of Virtual Reality Technology in the Inheritance and Dissemination of Non-posthumous Culture[C]. University of Science and Technology Liaoning.

8. Zhang,Y.Y.(2020)Research on the Influence of Short Video in New Media Age on Non-posthumous Culture Communication[J]. Media Forum.

9. Fan,X.Y.(2020)An Inquiry into the Situation Teaching of Junior Middle School Music Course Based on VR Technology[C]. Inner Mongol Normal University.

10. Shi,L.(2015)Study on the Participation of Music Education in Intangible Cultural Heritage in Jiangxi University[J].Theatre House.

11. Ren,F.Jiang,X.T.(2017)Study on the Protection of Intangible Cultural Heritage in Jiangxi Province[J]. Journal of Qiqihar University (philosophy and Social Sciences Edition).

12. Liu,J.Huang,J.M.Zhang,H.Y.(2019)Study on the Protection of Intangible Cultural Heritage in Jiangxi Province[J].Theatre House. 